\title{
INTER-RELAÇÃO ENTRE PROFESSORES DA SALA DE ATENDIMENTO EDUCACIONAL ESPECIALIZADO E DO ENSINO REGULAR
}

\author{
INTER-RELACIÓN ENTRE PROFESORES DE AULA DE ATENCIÓN \\ EDUCACIONAL ESPECIALIZADA Y DE LA ENSEÑANZA REGULAR
}
THE INTERPERSONAL RELATIONSHIP BETWEEN TEACHERS FROM SPECIALIZED EDUCATIONAL TEACHING AND REGULAR TEACHING ROOMS

\author{
Hellen Karolinni Rocha SOUZA ${ }^{1}$ \\ Kelly VITAL ${ }^{2}$ \\ Valéria de Oliveira DUARTE ${ }^{3}$ \\ Betania Jacob Stange LOPES ${ }^{4}$
}

RESUMO: O presente estudo teve por objetivo principal: mapear e analisar o nível e a forma de articulação entre os professores e as atividades desenvolvidas em Salas de Recursos Multifuncionais (SRMs) e salas comuns, em uma proposta inclusiva. Com o intuito de contribuir para o processo da educação inclusiva no ambiente escolar, estabeleceu-se aqui a abordagem quanti-qualitativa do tipo transversal. Utilizou-se um questionário para os professores de sala comum e professores de SRM. Participaram deste estudo dezesseis professores de sala comum que tinham alunos com deficiência e nove de SRM da rede pública de ensino de dois municípios da Região Metropolitana de Campinas. Para a análise de conteúdo dos questionários, tomou-se como referência a obra de Bardin, que aponta três fases fundamentais no processo: pré-análise, exploração do material e tratamento dos resultados. Por meio deste estudo, foi possível concluir que: (a) os professores estão cientes da importância da SRM e das atribuições dos professores que atuam nesse espaço - todavia, não parece estar claro o trabalho do professor da sala comum -, (b) há uma inter-relação entre professores de sala comum e SEM - todavia falta maior tempo destinado às trocas necessárias -, e (c) em alguns casos, há falta de entendimento do professor de sala comum sobre a sua função quanto ao aluno Público-Alvo da Educação Especial (PAEE).

PALAVRAS-CHAVE: Sala de recursos multifuncionais. Sala comum. Professores.

${ }^{1}$ Centro Universitário Adventistas de São Paulo (Unasp), Engenheiro Coelho - SP - Brasil. Graduanda no Curso de Licenciatura em Pedagogia. E-mail: hellenkarolinnisouza @ gmail.com.

${ }^{2}$ Centro Universitário Adventistas de São Paulo (Unasp), Engenheiro Coelho - SP - Brasil. Graduanda no Curso de Licenciatura em Pedagogia E-mail: kellyvitalcosta@ @otmail.com.

${ }^{3}$ Centro Universitário Adventistas de São Paulo (Unasp), Engenheiro Coelho - SP - Brasil. Graduanda no Curso de Licenciatura em Pedagogia E-mail: lela.duarte2208@gmail.com.

${ }^{4}$ Centro Universitário Adventistas de São Paulo (Unasp), Engenheiro Coelho - SP - Brasil. Doutora em Educação Especial pela UFSCar. E-mail: betania.stange@ unasp.edu.br. 
RESUMEN: La presente investigación tuvo como objetivo principal: mapear y analizar el nível de articulación entre los professores y las actividades desarrolladas en aulas de Recursos Multifuncionales (ARMs) y aulas comunes en una propuesta inclusiva. Con el fin de contribuir al proceso de la educación inclusiva en el ambiente escolar, se estableció aquí el abordaje cuantitativo y cualitativo del tipo transversal. Se utilizó un cuestionario para los profesores de aula común y profesores de ARM. Participaron de esta investigación dieciséis profesores de aula común que tenían alumnos con discapacidad y nueve de ARM de la red pública de enseñanza de dos municípios de la Región Metropolitana de Campinas. Para el análisis de contenido de los cuestionarios, se tomó como referencia la obra de Bardin, que señala tres fases fundamentales en el proceso: pre-análisis, exploración del material y tratamento de los resultados. Através de este estúdio, fue posible concluir que: (a) los profesores son conscientes de la importancia de la ARM y de las atribuciones de los profesores que actúan en ese espacio. Sin embargo, no quedó en claro el trabajo del profesor de aula común; (b) existe una interrelación entre profesores del aula común y ARM, pero falta mayor tempo destinado a los intercambios necesarios; $y(c)$ en algunos casos, hay falta de entendimiento del profesor de aula común sobre su función en cuanto al alumno público-objetivo de la educación especial (POEE).

PALABRAS-CLAVES: Aula de recursos multifunción. Aula común. Profesores.

ABSTRACT: The aim of this study was to register and analyze the shape and the communication level between teachers and the activities developed in Multifunctional Resource Classrooms (MRRs) and in ordinary classrooms (ORs) as a proposal to revolutionize inclusion of disabled students. In regard of contributing to the process of inclusive education in schools, a transversal quanti-qualitative approach was established. A questionnaire was used as a tool to assess teachers from ordinary rooms as well as teachers from MRRs. Thus, sixteen teachers from ORs and nine teachers from MRRs with disabled students from public schools from two cities in the region of Campinas were assessed. To analyze the content of the questionnaires, the work of Bardin was taken as a reference, in which three fundamental phases are highlighted in the learning process: pre-analysis, material research, and treatment of the results. Thus, it was possible to conclude that: (a) the teachers are aware of the importance of MRRs and their contributions in these rooms, however, this aspect is not clear among teachers from ORs; (b) there is an interpersonal relationship between teachers from MRRs and ORs, even though the time spent has not been enough; (c) in some cases, there is a lack of understanding in teachers from ORs regarding their role in DisabilityInclusive Education.

KEYWORDS: Multifunctional resource rooms. Ordinary rooms. Teachers.

\section{Introdução}

A proposta de inclusão escolar surgiu em decorrência de um processo histórico de lutas e reivindicações sociais de garantia aos direitos do educando Público-Alvo da 
Educação Especial (PAEE) ${ }^{3}$, conforme previsto no parecer Brasil (2001) quanto ao acesso e permanência na escola.

O fato de os alunos com deficiência estarem matriculados em uma instituição de ensino regular não significa que eles estejam recebendo um ensino de qualidade, tampouco garantem a sua permanência na escola. A qualidade de ensino é um elemento essencial para se alcançar o desenvolvimento de estudantes com e sem deficiência. Não basta inseri-los em sala de aulas comum, mas se faz necessária a adequação de todo o contexto escolar para atendê-los.

Com o aumento do número de matrículas nas escolas regulares, os profissionais da educação têm sido desafiados à elaborarem propostas educacionais com o objetivo de efetivar o atendimento educacional voltado para o aluno. O Atendimento Educacional Especializado (AEE) é uma dessas alternativas e é realizado em Salas de Recursos Multifuncionais (SRMs).

Segundo o Decreto n. ${ }^{\circ} 7.611 / 11$, a proposta contempla o atendimento em turno oposto àquele em que o aluno está matriculado e propõe uma inter-relação entre o professor da sala comum e o da Sala de Recurso Multifuncional (SRM), a fim de garantir a acessibilidade ao currículo e um ensino que proporcione aprendizagem e participação de todos (BRASIL, 2011). Contudo, na prática, essas prerrogativas não se confirmam, conforme afirmativa de pesquisadores tais como Araruna (2013), Buiatti (2013) e Delevatti (2012).

Diante desse contexto, surgiram as questões de pesquisa que nortearam este estudo: É possível estabelecer articulação entre os professore de AEE e do ensino regular? Quais ações emergem desse processo? Com base nesses questionamentos e na revisão da literatura sobre o tema, o presente estudo teve por objetivo principal, mapear e analisar o nível e a forma de articulação entre os professores e as atividades desenvolvidas nas SRMs e salas comuns em uma proposta inclusiva.

\section{Salas de Recursos Multifuncionais (SRM)}

A consolidação da Educação Especial, em uma perspectiva inclusiva, prevê a inserção do aluno PAEE em sala comum, conforme expressa a Lei de Diretrizes e Bases para Educação Nacional - LDBEN/96. Todavia, em seu artigo 58, a Lei explicita a

${ }^{3}$ É considerado aluno Público-Alvo da Educação Especial (PAEE) aquele com deficiência, transtornos globais do desenvolvimento e com altas habilidades/superdotação (BRASIL, 2011). 
necessidade de apoio específico a esse grupo de alunos por meio de uma relação entre Educação Especial e a Educação Comum.

De acordo com artigo 8..$^{\circ}$ da Resolução CNE/CEB n. ${ }^{\circ}$ 2/2001, a SRM é o local onde deve acontecer o AEE, tendo como objetivo apoiar os sistemas de ensino na oferta do AEE de forma complementar ou suplementar o processo de escolarização. Essas salas devem ser adequadas em espaço físico e modulação para atender às necessidades específicas dos alunos matriculados no AEE e devem, preferencialmente, estar inseridas nas escolas públicas e privadas de ensino básico regular no qual é oferecido o AEE (BRASIL, 2001).

O AEE deve acontecer no contraturno em que o aluno estuda, uma vez que ele não é substituição da escolarização regular em classes comuns. As atividades realizadas nessas salas devem ser distintas das atividades realizadas em sala regular. De acordo com Furlan (2014), o trabalho desenvolvido com o aluno PAEE baseia-se no brincar consciente, utilizando, assim: jogos pedagógicos que valorizam os aspectos lúdicos, a criatividade, o desenvolvimento de estratégias lógicas e o pensamento; músicas, jogos adaptados e jogos dramáticos auxiliando a criança a adquirir o domínio da comunicação que permite a relação lúdica com a realidade e a vivência social autêntica.

As SRM devem ter professores especializados em Educação Especial e ser equipadas com materiais didáticos e de acessibilidade específicos para que seja realizada a complementação e/ou suplementação curricular do aluno PAEE. Esses professores devem ser capazes de elaborar e executar recursos pedagógicos e de acessibilidade, assim como proposto no plano de AEE.

\section{Professor de sala de Atendimento Educacional Especializado (AEE)}

O papel do educador de salas de AEE é ser facilitador no processo pedagógico do aluno PAEE incluso em uma instituição de ensino regular. Suas funções são: observar a realidade do aluno, identificar problemas e criar possibilidades adequadas para a superação das barreiras que o impedem de se desenvolver plenamente na escola e fora dela; articular parcerias com outros profissionais de áreas afins; elaborar o plano de ação de AEE, propondo serviços e recursos de acessibilidade ao conhecimento; orientar professores do ensino regular e familiares do PAEE na utilização de novos materiais e recursos que o auxiliem em seu desenvolvimento. 
Para que o professor do AEE desenvolva esse complexo trabalho de forma eficaz, um dos fatores essenciais é uma formação voltada para educação inclusiva. A Resolução n. ${ }^{\circ}$, de 2009, indica que “[...] para a atuação no AEE, o professor deve ter formação inicial que o habilite para o exercício da docência e uma formação na área de Educação Especial” (BRASIL, 2009, p. 3). Entretanto, não há uma especificação acerca do conhecimento nem de formação específica necessários ao professor do AEE com base no trabalho a ser desenvolvido na SRM.

Já o Decreto n. ${ }^{\circ}$ 7.611, de 17 de novembro de 2011, aponta a necessidade da formação continuada dos educadores das salas de AEE para atender às necessidades específicas de seus alunos, como, por exemplo, a necessidade do aprendizado da educação bilíngue em situações em que haja estudantes surdos ou com deficiência auditiva ou do ensino do braile para estudantes cegos ou com baixa visão.

\section{Professor de sala comum}

Um dos pilares para a construção da inclusão escolar é uma política de formação dos educadores, de acordo com o Projeto de Lei 5.395/09, que prevê que professores dos anos iniciais do Ensino Fundamental devem ser licenciados em Pedagogia. O trabalho pedagógico do professor da classe comum deve ser qualificado para responder às necessidades diferenciadas de seus alunos e para propor situações de ensino e aprendizagem satisfatórios para todos (MENDES, 2006).

Nesse contexto, a formação de professores deve ser voltada para os princípios da política da inclusão e deveria contemplar na formação inicial “[...] um preparo de efetiva qualidade para lidar com a diversidade, além de (in) formação específica em Educação Especial, no curso de formação inicial - [...] graduação - pedagogia" (DENARI, 2006, p. 37).

O professor de classe comum deve atuar como facilitador no processo de inclusão, e para tanto, precisa conhecer os elementos necessários para atuação com seu aluno PAEE, a fim de identificar as suas especificidades e seu potencial de desenvolvimento, para, então, poder desenvolver atividades mais eficazes, contribuindo para que esse aluno atinja um nível mais elevado de desenvolvimento e se beneficie do processo de inclusão. 
Flavey, Givner e Kimm (1999) afirmaram que em espaços educacionais inclusivos o ensino deve estar centrado nas potencialidades, nos interesses e nas necessidades dos alunos. Elas indicam que, depois das avaliações iniciais para identificar as potencialidades e as necessidades educacionais do aluno PAEE e seu grau de desempenho atual, é importante que o professor mantenha uma avaliação contínua sobre o que ensinar, como ensinar e quando mudar o ensino. Para isso, as autoras enfatizaram o uso das avaliações informais ${ }^{4}$ para obter informações importantes na tomada de decisões educacionais. As autoras fazem a ressalva de que, algumas vezes, mesmo com o uso de várias estratégias de ensino, o aluno pode não entender as disciplinas acadêmicas, sendo necessário o uso de alternativas, como ensino do mesmo currículo, porém adaptado às possibilidades do aluno PAEE.

É de grande importância, da mesma forma, que o professor trabalhe de forma colaborativa com outros profissionais da educação a fim de perceberem os avanços e retrocessos de seus alunos. As parcerias são essenciais para que se atinja o máximo do desenvolvimento das potencialidades do aluno, pois ninguém é possuidor de todos os saberes.

\section{Inter-relação da sala regular com a sala de Atendimento Educacional Especializado (AEE) e as ações que resultam desta inter-relação}

Conforme determina o Decreto n. ${ }^{\circ} 7.611 / 11$, os professores das classes comuns e do AEE devem se articular a fim de garantir a acessibilidade ao currículo e um ensino que proporcione aprendizagem e participação de todos. Segundo Cia e Rodrigues (2013), os professores que atuam em SRM tem o desafio de estabelecer uma relação de troca e colaboração com os professores regulares de seus alunos visando obter informações adicionais sobre o desempenho destes e gerar maior probabilidade de que o trabalho desenvolvido nas SRM repercuta nas classes comuns.

Considera-se de suma importância a parceria entre os professores de SRM e os professores de sala regular para um melhor e mais efetivo desenvolvimento dos alunos atendidos pelo AEE e há necessidade de se compreender a forma como essa relação vem sendo estabelecida.

Em estudos feitos por Costa e Dantas (2014), analisou-se que o principal entrave da articulação entre a sala comum e o AEE para a construção de práticas pedagógicas

\footnotetext{
${ }^{4}$ Aquelas que se dão pela interação dos alunos com o professor e com os demais alunos dentro de todos
} os espaços de trabalho escolar. 
inclusivas é a falta de diálogo, justificada principalmente pela escassez de tempo e pela falta de apoio da gestão escolar e de conhecimento. Além disso, a falta de compreensão dos professores regulares sobre o trabalho a ser desenvolvido pelo professor de AEE e um plano de atendimento que contemple o apoio ao professor, com observações em sala de aulas e momentos de trocas para sugestões, tem dificultado a construção de práticas pedagógicas inclusivas.

\section{Metodologia}

Com o intuito de contribuir para o processo da educação inclusiva no ambiente escolar, estabeleceu-se neste estudo a abordagem quanti-qualitativa, uma vez que "[...] o estudo quantitativo pode gerar questões a serem aprofundadas qualitativamente e viceversa" (MINAYO, 1993). Nesse contexto, o qualitativo e o quantitativo não podem ser pensados como contradição, mas como análise de aspectos palpáveis e compreensão mais ampliada do tema estudado. Essa ideia é ratificada por Gerhardtt (2009) ao afirmar que "[...] a pesquisa pode ser feita pelo método misto, quantitativo qualitativo, de modo a obter uma compreensão e mais ampliada do estudo".

A pesquisa quanti-qualitativa assume variadas formas. Neste estudo, optou-se pelo tipo transversal, em que as mediações são realizadas por meio de uma amostragem em um único 'momento'. A investigação para o estudo aconteceu a partir da aplicação de questionário para professores de escolas públicas.

\section{Participantes e local}

Participaram deste estudo dezesseis professores de sala comum que tinham alunos com deficiência e nove de SRM da rede pública de ensino de dois municípios da Região Metropolitana de Campinas.

\section{Coleta e análise dos dados}

Utilizou-se um questionário para os professores de sala comum e professores de SRM. O questionário era composto por cinco blocos, sendo que: o primeiro continha dados de identificação; o segundo, dados de formação; o terceiro, dados profissionais; e 
o quarto, perguntas abertas sobre a atuação do professor e a inter-relação entre o professor da sala de aula comum e o da SRM.

Após o contato com a Secretaria de Educação de cada município para obtenção de autorização para a realização da pesquisa nas escolas municipais, realizaram-se contatos com os diretores de cada unidade escolar. Após as autorizações, ocorreu um encontro com as professoras das salas comuns e SRM com o intuito de se esclarecer o objetivo da pesquisa, bem como os procedimentos da coleta de dados. Foram entregues o Termo de Consentimento Livre e Esclarecido e o questionário para as professoras que aceitaram participar do estudo.

O questionário foi elaborado com base nos objetivos da pesquisa, e para a análise de conteúdo dos questionários tomou-se como referência a obra de Bardin (2011). Segundo Chizzoti (2006, p. 98), a análise de conteúdo tem como objetivo “[...] compreender criticamente o sentido das comunicações, seu conteúdo manifesto ou latente, as significações explícitas ou ocultas" (CHIZZOTI, 2006, p. 98). Em uma interpretação de texto, aponta três fases fundamentais nesse processo, a saber: (a) préanálise, fase de organização do material a ser analisado com a finalidade de torná-lo operacional, sistematizando as ideias iniciais, fase de decisão de instrumento e formulação das questões norteadoras da pesquisa; (b) exploração do material, que consiste nas operações da codificação, da classificação e da categorização do material; e (c) tratamento dos resultados, ou seja, os resultados brutos são tratados para se tornarem significativos e válidos. É a etapa em que os pesquisadores podem propor inferências e interpretações a partir do quadro teórico e dos objetivos propostos para a pesquisa.

\section{Resultados}

A inter-relação entre professores de sala comum e SRM permite desenvolvimento mais efetivos do aluno PAEE. Torna-se, portanto, relevante ponderar as falas dos professores a partir dos questionários que eles responderam. Quanto aos discursos contidos em suas respostas, podem-se observar suas opiniões quanto à interrelação que existe entre eles, de acordo com o disposto na Tabela 1.

Tabela 1: Opinião dos professores quanto à sua inter-relação com os professores de sala de recursos 


\begin{tabular}{|c|c|c|c|}
\hline Categorias & $\begin{array}{l}\text { Número de } \\
\text { respostas }\end{array}$ & $\begin{array}{l}\text { Percentual de } \\
\text { respostas para } \\
\text { quantitativo de } \\
\text { participantes }\end{array}$ & $\begin{array}{l}\text { Percentual de } \\
\text { respostas } \\
\text { para } \\
\text { quantitativo } \\
\text { de aspectos } \\
\text { enunciados }\end{array}$ \\
\hline $\begin{array}{l}\text { Contatos durante o HTPC } \\
\text { Trabalho Pedagógico Coletivo) }\end{array}$ & 19 & $76 \%$ & $58 \%$ \\
\hline Sempre que necessário & 9 & $36 \%$ & $27 \%$ \\
\hline Contatos por meio de relatórios & 4 & $16 \%$ & $12 \%$ \\
\hline Contatos no período de aulas especiais & 1 & $4 \%$ & $3 \%$ \\
\hline Total & 33 & & $100 \%$ \\
\hline
\end{tabular}

Fonte: Professores participantes do estudo / 25 respondentes. Cosmópolis e Artur Nogueira, SP, 2016.

Analisando a tabela acima, nota-se que $76 \%$ dos professores participantes relataram que seu contato com o professor de sala comum e/ou SRM ocorreu durante o horário de HTPC. Conforme expressou a professora PRC03: "Eu encontro a professora nos horários das reuniões pedagógicas. Fora este horário não temos contato". De acordo com a Portaria n. ${ }^{\circ}$ 01, de 1996, os HTPC devem ser desenvolvidas reuniões na Unidade Escolar pelos professores e pelo professor-coordenador pedagógico para estimular o desenvolvimento das atividades coletivas da Unidade Escolar. Essas reuniões já têm uma pauta específica, e o tempo é escasso para um planejamento específico das necessidades de aluno PAEE.

Pelas respostas dos professores, verificou-se que 36\% deles se comunicam e se relacionam sempre que necessário, muito embora não tenha sido possível dimensionar a periodicidade e a forma como se dão esses encontros. Mantoan (2011) valorizou esses momentos e esclareceu que cada professor tem um papel no desenvolvimento do aluno: ao professor da sala de aula comum é atribuído o ensino das áreas do conhecimento; e ao professor do AEE cabe complementar/suplementar a formação do aluno com conhecimentos e recursos específicos que eliminam as barreiras as quais impedem ou limitam sua participação com autonomia e independência nas turmas comuns do ensino regular.

Nota-se ainda que $16 \%$ dos professores interagiram somente por meio de relatórios, de forma impessoal, e apenas $4 \%$ relataram que mantêm contato durante o período de aulas especiais pelo fato de terem mais tempo para discutir o assunto. Segundo Mantoan (2011), as necessidades educacionais específicas devem ser atendidas 
no dia a dia escolar e com todos os que atuam no ensino regular e Educação Especial com a finalidade de aproximar o aluno PAEE do ambiente comum de formação de todos.

Tabela 2: Opinião dos professores quanto à diferença do trabalho na sala comum e SRM

\begin{tabular}{|c|c|c|c|c|}
\hline Categorias & Subcategorias & $\begin{array}{l}\text { Número de } \\
\text { respostas }\end{array}$ & $\begin{array}{l}\text { Percentual de } \\
\text { respostas } \\
\text { para } \\
\text { quantitativo } \\
\text { de } \\
\text { participantes } \\
\end{array}$ & $\begin{array}{l}\text { Percentual } \\
\text { de respostas } \\
\text { para } \\
\text { quantitativo } \\
\text { de aspectos } \\
\text { enunciados } \\
\end{array}$ \\
\hline \multirow{7}{*}{ Sala de recursos } & $\begin{array}{l}\text { Atividades desenvolvidas } \\
\text { individualmente }\end{array}$ & 16 & $64 \%$ & $29 \%$ \\
\hline & $\begin{array}{l}\text { A sala possui ambiente, } \\
\text { horário diferenciado, materiais } \\
\text { específicos e atividades } \\
\text { adaptadas }\end{array}$ & 10 & $40 \%$ & $18 \%$ \\
\hline & $\begin{array}{l}\text { Atividades realizadas em } \\
\text { pequenos grupos }\end{array}$ & 6 & $24 \%$ & $11 \%$ \\
\hline & $\begin{array}{l}\text { Trabalho realizado por } \\
\text { vivências lúdicas }\end{array}$ & 4 & $16 \%$ & $8 \%$ \\
\hline & Trabalho centrado nos alunos & 2 & $8 \%$ & $4 \%$ \\
\hline & $\begin{array}{l}\text { O professor possui uma } \\
\text { formação específica }\end{array}$ & 1 & $4 \%$ & $2 \%$ \\
\hline & Total & 39 & & $72 \%$ \\
\hline \multirow{4}{*}{ Sala comum } & $\begin{array}{l}\mathrm{O} \text { aluno PAEE realiza as } \\
\text { mesmas atividades que seus } \\
\text { pares sem deficiência }\end{array}$ & 10 & $40 \%$ & $19 \%$ \\
\hline & Maior número de alunos & 4 & $16 \%$ & $7 \%$ \\
\hline & $\begin{array}{l}\text { Limitações para atender alunos } \\
\text { de inclusão }\end{array}$ & 1 & $4 \%$ & $2 \%$ \\
\hline & Total & 15 & & $28 \%$ \\
\hline Total & & 54 & & $100 \%$ \\
\hline
\end{tabular}

Fonte: Professores participantes do estudo / 25 respondentes. Cosmópolis e Artur Nogueira, SP, 2016.

Ao analisar a Tabela 2, foi possível perceber que $72 \%$ dos professores caracterizaram as SRM e apenas $28 \%$ falaram das salas comuns sem falar como o trabalho deveria ser desenvolvido nesse espaço. Eles não pontuaram a diferença existente entre as duas salas. Todavia, cada uma tem a sua função independentemente dos desafios enfrentados pelos dois grupos de professores. 
Tabela 3: Opinião dos professores quanto aos elementos facilitadores e dificultares na articulação da relação entre o professor de sala comum e SRM

\begin{tabular}{|c|c|c|c|c|}
\hline Categorias & Subcategorias & $\begin{array}{l}\text { Número de } \\
\text { respostas }\end{array}$ & $\begin{array}{l}\text { Percentual de } \\
\text { respostas para } \\
\text { quantitativo de } \\
\text { participantes }\end{array}$ & $\begin{array}{l}\text { Percentual de } \\
\text { respostas para } \\
\text { quantitativo } \\
\text { de aspectos } \\
\text { enunciados } \\
\end{array}$ \\
\hline \multirow{7}{*}{ Elementos Facilitadores } & $\begin{array}{l}\text { HTPC (reuniões pedagógicas) e } \\
\text { conselhos de classe }\end{array}$ & 13 & $52 \%$ & $20 \%$ \\
\hline & $\begin{array}{l}\text { Interação entre os professores } \\
\text { da sala de AEE e sala regular } \\
\text { possibilitando diferentes visões } \\
\text { e trocas de experiências }\end{array}$ & 8 & $32 \%$ & $13 \%$ \\
\hline & $\begin{array}{l}\text { Envolvimento de ambas as } \\
\text { professoras (SRM e sala } \\
\text { comum) na aprendizagem do } \\
\text { aluno }\end{array}$ & 6 & $24 \%$ & $9 \%$ \\
\hline & $\begin{array}{l}\text { Maior participação da } \\
\text { professora de sala AEE na } \\
\text { rotina da sala de aula comum, } \\
\text { acréscimo no número de } \\
\text { profissionais e apoio da equipe } \\
\text { gestora }\end{array}$ & 4 & $16 \%$ & $6 \%$ \\
\hline & $\begin{array}{l}\text { Planejamento e materiais } \\
\text { específicos para atender as } \\
\text { demandas do aluno PAEE }\end{array}$ & 3 & $12 \%$ & $5 \%$ \\
\hline & Relatórios & 2 & $8 \%$ & $3 \%$ \\
\hline & Total & 36 & & $56 \%$ \\
\hline
\end{tabular}

A diferença de horário de trabalho entre a professora de sala comum e de recursos e o pouco tempo que as professoras $13 \quad 52 \% \quad 20 \%$ têm para conversarem sobre os alunos

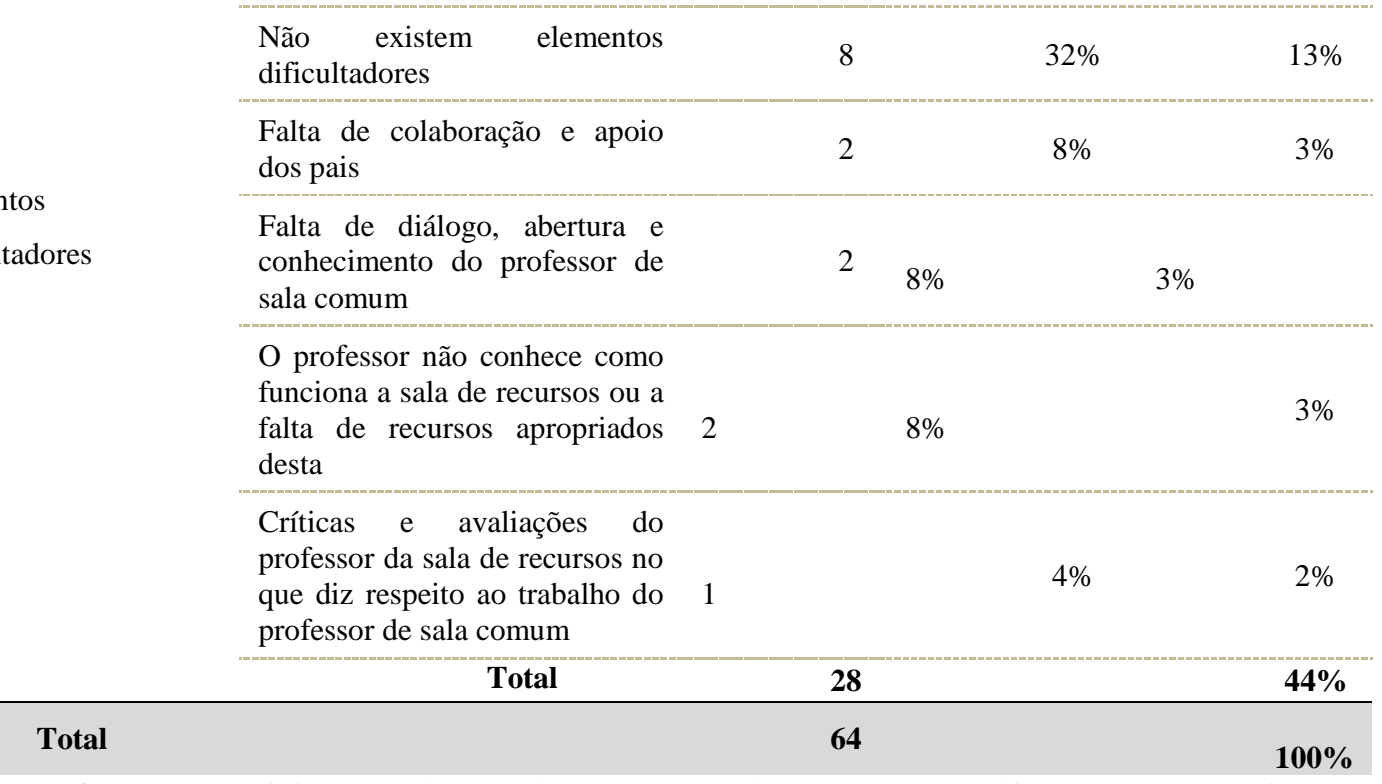

Elementos

Dificultadores

Fonte: Professores participantes do estudo / 25 respondentes. Cosmópolis e Artur Nogueira, SP, 2016. 
Na Tabela 3, foi realizada uma análise sobre os facilitadores e dificultadores no processo de inter-relação entre os professores de sala comum e SRM. Observou-se que $52 \%$ dos professores apontaram que as reuniões de HTPC são elementos facilitadores na articulação entre as duas salas. A Hora de Trabalho Pedagógico Coletivo (HTPC) tem o intuito de reunir professores e coordenadores para a discussão, análise e proposição de soluções que possam atender às necessidades educacionais coletivas apresentadas periodicamente. Todavia, para questões mais específicas se fazem necessários encontros mais intencionais, conforme informação trazida por $32 \%$ dos professores, sendo que $24 \%$ valorizaram o envolvimento de ambas as professoras (sala comum e SRM) no processo de ensino/aprendizagem, mesmo com funções distintas.

A articulação entre professores que atuam em sala de aulas comum e de AEE, para promover as condições adequadas de participação e aprendizagem dos alunos, é aspecto fundamental para o processo de inclusão, orientada inclusiva em dispositivos legais, como a NT n. ${ }^{\circ} 11 / 2010$ (BRASIL, 2010).

Em contraponto, 52\% apontaram como complicador o fato de que o aluno PAAE frequentar a sala de SRM no contraturno dificulta o encontro desses professores para esclarecimentos e para tirar dúvidas, conforme expôs o professor PR02: "se a professora da sala de AEE permanecesse o período todo seria mais fácil, a meu ver, a comunicação e retirar duvidas". Porém, 32\% dos professores alegaram não existirem elementos dificultadores na inter-relação entre esses dois grupos de profissionais.

\section{Conclusão}

O presente trabalho foi elaborado pensando em profissionais que acompanham alunos PAEE no processo de aprendizagem no espaço escolar e professores de sala comum e SRM pelo fato de estabelecerem uma relação direta com os alunos em processo de inclusão.

Por meio deste estudo, pode-se concluir, de maneira geral, que: (a) os dois grupos de professores estão cientes da importância da SRM e das atribuições dos professores que atuam nesse espaço. Todavia, não parece estar claro o trabalho do professor da sala comum; (b) há uma inter-relação entre professores de sala comum e SRM, na medida do possível, todavia falta maior tempo destinado às trocas necessárias; e (c) em alguns casos, há falta de entendimento do professor de sala comum sobre a sua função quanto ao aluno PAEE e ao processo inclusivo, atribuindo a responsabilidade do 
insucesso ao professor da SRM, o que dificulta a efetivação da aproximação entre os dois grupos de profissionais.

Para se fortalecer um trabalho em parceria, há necessidade de se compreender que as funções essenciais do professor de classe comum e do professor da SRM são diferentes, porém interdependentes. Enquanto o primeiro necessita encontrar alternativas que favoreçam a participação de seus alunos PAEE no processo de ensino/aprendizagem junto a seus pares na sala de aulas comum, o segundo deve oportunizar aos mesmos alunos a descoberta de suas potencialidades, contribuindo para o desenvolvimento destes e ampliação de participação na sala de aula comum.

Para se ter o processo de inclusão no ambiente escolar, fazem-se necessárias rupturas de práticas exclusivas para proporcionar condições para melhorias no atendimento a esse grupo de alunos por meio de maior interação entre os professores da sala comum e SRM.

\section{REFERÊNCIAS}

ARARUNA, M. R. Dos desafios às possibilidades: a prática pedagógica do professor do Atendimento Educacional Especializado com aluno que apresenta deficiência intelectual. 2013, 281f. Dissertação (Mestrado em Educação Brasileira). Programa de Pós-Graduação em Educação Brasileira - Universidade Federal do Ceará, Fortaleza: 2013.

BARDIN, L. Análise de Conteúdo. São Paulo: Edições 70, 2011.

BRASIL Ministério da Educação, Secretaria de Educação Especial. Esplanada dos Ministérios. Nota Técnica - seesp/gab/n. ${ }^{\circ}$ 11/2010.

BRASIL. Ministério da Educação, Conselho Nacional de Educação Câmara de Educação Básica. Resolução n. ${ }^{\circ}$ 4, de 2009. Disponível em:

<http://portal.mec.gov.br/dmdocuments/rceb004_09.pdf>. Acesso em: 20 jan. de 2017.

BRASIL. Ministério da Educação. Decreto n. ${ }^{\circ}$ 7.611, de 17 de novembro de 2011. Dispõe sobre a educação especial, o atendimento educacional especializado e dá outras providências. Diário oficial da União, Brasília, 18 de nov. 2011.

BRASIL. Ministério da Educação. Lei de Diretrizes e Bases da Educação Nacional, LDB 9.394, de 20 de dezembro de 1996.

BRASIL. Ministério da Educação. Parecer n. ${ }^{\circ}$ 17, de 3 de julho de 2001. Dispõe sobre as Diretrizes Nacionais para a Educação Especial na Educação Básica. Diário oficial da União, Brasília, 17 de ago. 2001. 
BRASIL. Ministério da Educação. Resolução CNE/CEB n. ${ }^{\circ}$ 2, de 11 de setembro de 2001. Institui Diretrizes Nacionais para a Educação Especial na Educação Básica. 2011.

BRASIL. Portaria Cenp n. 1/96 L.C. n. ${ }^{\circ}$ 836/97.

BRASIL. Projeto de lei 5.395/09, disponível em:

<http://www.camara.gov.br/proposicoesWeb/fichadetramitacao?idProposicao=438125> Acesso em: 2 de abr. 2017.

BUIATTI, V.P. Atendimento Educacional Especializado: dimensão política, formação docente e concepções dos profissionais. 2013. 320f. Tese (Doutorado). Programa de Pós-graduação em Educação, Universidade de Uberlândia, Uberlândia, 2013.

CHIZZOTI, A. Pesquisa qualitativa em ciências humanas e sociais. Petrópolis, RJ: Vozes, 2006.

CHIZZOTTI, A. Pesquisa em ciências humanas e sociais. 8. ed. São Paulo: Cortez. 2006.

CIA, F.; RODRIGUES, R. K. G. As Relações do Professor de Salas de Recursos Multifuncionais Pré-Escolar: A Escola, O Professor da Classe Comum e as Instituições Especializadas. VIII Encontro da Associação Brasileira de Pesquisadores em Educação Especial. Londrina de 05 a 07 de novembro de 2013 - ISSN 2175-960x. Disponível em: <file:///C:/Users/User/Documents/AT14-018.pdf>. Acesso em: 1 jun. 2017.

COSTA, L. L.; DANTAS, L. M. A Relação Entre as Práticas Pedagógicas do AEE e da sala de aula comum em uma escola pública regular de Horizonte CE.CINTEDI.

Congresso Internacional de Educação Inclusiva. Disponível em: <http://editorarealize.com.br/revistas/cintedi/trabalhos/Modalidade_1datahora_10_11_2 014_18_46_51_idinscrito_3930_8539bf7b96c2e0293b1928242ccf7b31.pdf>. Acesso em: 25 abr. 2017.

DELEVATTI, A. C. Atendimento Educacional Especializado: que atendimento é este? As configurações do AEE na perspectiva da rede municipal de ensino de Gravataí/RS. 2012. 143f. Dissertação (Mestrado em Educação) - Pós-Graduação em Educação, Universidade Federal do Rio Grande do Sul, Porto Alegre, 2012.

DENARI, F. E. Um (novo) olhar sobre a formação do professor de educação especial: da segregação à inclusão. In: RODRIGUES, D. (Org.). Inclusão e educação: doze olhares sobre a educação inclusiva. São Paulo: Summus, 2006. p. 35-63;

FALVEY, M. A.; GIVNER, C. C.; KIMM, C. O que eu farei segunda-feira pela manhã? In: S. B. Stainback; W. Stainback. Inclusão: um guia para educadores. Porto Alegre: Artmed, 1999.

FURLAN S. M. A. Métodos e Tecnicas de Ensino Utilizados na Sala de Recursos Multifuncionais - Atendimento Educacional Especializado. Universidade Tecnológica Federal do Paraná. 2014. Disponível em: 
<http://repositorio.roca.utfpr.edu.br/jspui/bitstream/1/4229/1/MD_EDUMTE_2014_2_6 .pdf>. Acesso em: 1 jun. 2017.

GEHARDTT, T. H., SILVEIRA, D. T. Métodos de pesquisa. Porto Alegre Editora da universidade Federal do Rio Grande do Sul, 2009.

MANTOAN, M. T. E. SANTOS, M. T. C. T. FIGUEIREDO, R. V. Fascículo da Educação Especial. Ministério da Educação e Cultura - MEC, Brasília, 2011.

MENDES, E. G. A radicalização do debate sobre inclusão escolar no Brasil. Revista Brasileira de Educação, Campinas, v. 11, n. 33, 2006, p. 387-405.

MINAYO, M. C. S., SANCHES, O. Quantitativo-qualitativo: Oposição ou complementaridade? In: Caderno de Saúde Pública da Escola Nacional de Saúde Pública da Fiocruz. Rio de Janeiro: Fiocruz, jul. /set 1993.

\section{Como referenciar este artigo}

SOUZA, Hellen Karolinni Rocha et al. Inter-relação entre professores da sala de atendimento educacional especializado e do ensino regular. Revista on line de Política e Gestão Educacional, Araraquara, v. 21, n. esp. 02, p. 1048-1062, nov. 2017. Disponível em: <http://dx.doi.org/10.22633/rpge.v21.n.esp2.2017.10444>. EISSN:1519-9029.

Submetido em: 28/09/2017

Aprovado em: 12/11/2017 